\title{
Article \\ Gene Doping with Peroxisome-Proliferator-Activated Receptor Beta/Delta Agonists Alters Immunity but Exercise Training Mitigates the Detection of Effects in Blood Samples
}

\author{
Brigitte Sibille ${ }^{1} \mathbb{D}$, Isabelle Mothe-Satney ${ }^{1}$, Gwenaëlle Le Menn ${ }^{1}$, Doriane Lepouse ${ }^{1}$, Sébastien Le Garf ${ }^{1}$, \\ Elodie Baudoin ${ }^{1}$, Joseph Murdaca ${ }^{1}$, Claudine Moratal ${ }^{1}$, Noura Lamghari ${ }^{1}$, Giulia Chinetti ${ }^{2}$, Jaap G. Neels ${ }^{1, *},+(\mathbb{D}$ \\ and Anne-Sophie Rousseau $1,+$
}

check for

updates

Citation: Sibille, B.; Mothe-Satney, I.; Le Menn, G.; Lepouse, D.; Le Garf, S.; Baudoin, E.; Murdaca, J.; Moratal, C.; Lamghari, N.; Chinetti, G.; et al. Gene Doping with Peroxisome-ProliferatorActivated Receptor Beta/Delta Agonists Alters Immunity but Exercise Training Mitigates the Detection of Effects in Blood Samples. Int. J. Mol. Sci. 2021, 22, 11497. https://doi.org/10.3390/ ijms222111497

Academic Editors

Manuel Vázquez-Carrera and Walter Wahli

Received: 24 September 2021

Accepted: 23 October 2021

Published: 25 October 2021

Publisher's Note: MDPI stays neutral with regard to jurisdictional claims in published maps and institutional affiliations.

Copyright: (C) 2021 by the authors Licensee MDPI, Basel, Switzerland. This article is an open access article distributed under the terms and conditions of the Creative Commons Attribution (CC BY) license (https:// creativecommons.org/licenses/by/ $4.0 /)$
1 INSERM, Université Côte d'Azur, C3M, 06204 Nice, France; Brigitte.SIBILLE@univ-cotedazur.fr (B.S.); Isabelle.SATNEY@univ-cotedazur.fr (I.M.-S.); gwenaelle.lemenn@gmail.com (G.L.M.); dlepouse@gmail.com (D.L.); seb.legarf@hotmail.fr (S.L.G.); elodiebaudoin68@gmail.com (E.B.); joseph.murdaca@univ-cotedazur.fr (J.M.); Claudine.MORATAL@univ-cotedazur.fr (C.M.); nouritalamghari@gmail.com (N.L.); Anne-Sophie.ROUSSEAU@univ-cotedazur.fr (A.-S.R.)

2 CHU, INSERM, Université Côte d'Azur, C3M, 06204 Nice, France; Giulia.CHINETTI@univ-cotedazur.fr

* Correspondence: jaap.neels@univ-cotedazur.fr; Tel.: +33-(0)-4-89-15-38-40

+ These authors shared last authorship.

Abstract: Synthetic ligands of peroxisome-proliferator-activated receptor beta/delta (PPAR $\beta / \delta$ ) are being used as performance-enhancing drugs by athletes. Since we previously showed that PPAR $\beta / \delta$ activation affects T cell biology, we wanted to investigate whether a specific blood T cell signature could be employed as a method to detect the use of PPAR $\beta / \delta$ agonists. We analyzed in primary human $T$ cells the in vitro effect of PPAR $\beta / \delta$ activation on fatty acid oxidation (FAO) and on their differentiation into regulatory $\mathrm{T}$ cells (Tregs). Furthermore, we conducted studies in mice assigned to groups according to an 8-week exercise training program and/or a 6-week treatment with $3 \mathrm{mg} / \mathrm{kg} /$ day of GW0742, a PPAR $\beta / \delta$ agonist, in order to (1) determine the immune impact of the treatment on secondary lymphoid organs and to (2) validate a blood signature. Our results show that PPAR $\beta / \delta$ activation increases FAO potential in human and mouse $T$ cells and mouse secondary lymphoid organs. This was accompanied by increased Treg polarization of human primary $\mathrm{T}$ cells. Moreover, Treg prevalence in mouse lymph nodes was increased when PPAR $\beta / \delta$ activation was combined with exercise training. Lastly, PPAR $\beta / \delta$ activation increased FAO potential in mouse blood $\mathrm{T}$ cells. Unfortunately, this signature was masked by training in mice. In conclusion, beyond the fact that it is unlikely that this signature could be used as a doping-control strategy, our results suggest that the use of PPAR $\beta / \delta$ agonists could have potential detrimental immune effects that may not be detectable in blood samples.

Keywords: peroxisome-proliferator-activated receptor; fatty acid oxidation; doping control regulatory T cells; inflammation; exercise

\section{Introduction}

The nuclear receptor peroxisome-proliferator-activated receptor beta/delta (PPAR $\beta / \delta$ ) plays an important role in muscle physiology [1]. This transcription factor can be activated by endogenous natural ligands, such as certain lipid metabolites, or synthetic ligands, such as GW501516 and GW0742 [1]. The latter substances have also been called "exercise pills" or "exercise mimetics", since they were shown to affect the expression of endurance-related genes and metabolic pathways leading to increased exercise endurance [2]. While synthetic $\operatorname{PPAR} \beta / \delta$ agonists so far have not been approved for clinical purposes for treating diseases such as dyslipidemia due to the discovery of carcinogenic properties in preclinical studies on animals, these substances are being abused for performance-enhancing purposes in both humans and horses $[3,4]$. Therefore, since 2009, the list of prohibited substances and 
methods of doping, as established by the World Anti-Doping Agency, includes PPAR $\beta / \delta$ agonists. Methods to detect PPAR $\beta / \delta$ agonists are mostly focused on GW501516, and tests were developed for both blood and urine samples [5]. However, the emergence of new substances of this class means that new methods need to be developed that will allow the detection of any PPAR $\beta / \delta$ agonist. One method could be to identify a blood signature that would be specific for PPAR $\beta / \delta$ activation. In this respect, our laboratory has previously published several studies demonstrating that PPAR $\beta / \delta$ activation induces significant immunometabolic changes in $\mathrm{T}$ cells. We showed that in vitro and in vivo treatment with GW0742 led to an increase in the mRNA levels of three genes involved in fatty acid oxidation (i.e., Acaa2, Acadvl, and Cpt1a) in isolated mouse primary T cells and lymph nodes, respectively, resulting in increased fatty acid oxidation (FAO) in these cells [6]. Furthermore, increased PPAR $\beta / \delta$ activity had an impact on T cell development in the thymus, resulting in reduced production of $\alpha \beta$-T cells, while $\gamma \delta$-T cell production was unaffected. This led to a decrease in the $\alpha \beta / \gamma \delta \mathrm{T}$ cell ratio in peripheral tissues, including blood.

Regulatory $\mathrm{T}$ cells (Tregs) are a subset of $\mathrm{T}$ cells important for maintaining selftolerance by downregulating the immune response, and they do so by secreting immunoregulatory cytokines, such as TGF- $\beta$ and IL-10, which act to suppress the activity and function of immune effector cells (e.g., CD4+ and CD8+ T cells, monocytes/macrophages, natural killer cells, and dendritic cells) [7]. While mouse Tregs have a certain flexibility in metabolic fuel choice, they have a preference for FAO [8]. It was therefore not unexpected, given our above-mentioned result showing an increased FAO in $\mathrm{T}$ cells following activation of PPAR $\beta / \delta$, that we observed an increased prevalence of CD4+FOXP3+ Tregs in mouse lymph nodes after in vivo GW0742 treatment [9].

Whether these observed PPAR $\beta / \delta$-induced changes in T cell parameters can be used as a blood signature for detection of the use of PPAR $\beta / \delta$ agonists depends on whether these changes are specific to PPAR $\beta / \delta$ activation and are not also potentially induced by other factors such as acute or chronic exercise. Exercise-induced immune changes have been described previously [10]. Many of them affect the Treg population or the ability of T cells to produce pro/anti-inflammatory cytokines [10,11]. However, the ability of physical fitness or exercise to directly modify the metabolism of immune cells is unproven [12] but could be involved in these changes.

Our objective in this study was to confirm, in human T cells, our previous published observations in mouse T cells, that PPAR $\beta / \delta$ activation leads to an increase in FAO. Likewise, we also wanted to determine the effect of PPAR $\beta / \delta$ activation on the induction of Treg polarization in human T cells. Furthermore, we investigated whether exercise training would interfere with the effects of PPAR $\beta / \delta$ activation on FAO gene expression, $\mathrm{T}$ cell ratios, and Treg polarization.

\section{Results}

\subsection{In Vitro Treatment of Human T Cells with GW0742 Increases Their FAO Potential and} Polarization in Tregs

We hypothesized that GW0742, a PPAR $\beta$ / $\delta$ agonist, preconditions human T cells and favors their polarization toward the Treg subtype. To validate this hypothesis, we isolated PBMCs (peripheral blood mononuclear cells) from human buffy coats and performed monocyte depletion by adhesion. The remaining cells, enriched in lymphocytes, were placed in culture, activated with beads coated with $\alpha \mathrm{CD} 3$ and $\alpha \mathrm{CD} 28$ antibodies and IL-2, and treated with $1 \mu \mathrm{M}$ GW0742 or left untreated for 6 days. We showed (Figure 1A) a significant fourfold induction by GW0742 treatment of carnitine palmitoyl transferase 1a (CPT1a) mRNA that encodes the enzyme limiting the entry of fatty acids into the mitochondria, leading to a 2.6-fold increase in palmitate oxidation (Figure 1B). However, no difference in PPAR $\beta / \delta$ mRNA level was observed (Figure 1A). As already demonstrated in mouse T cells from secondary lymphoid organs [6], activation of the PPAR $\beta / \delta$ pathway in human blood $\mathrm{T}$ cells induces the expression of genes encoding FAO proteins (CPT1a) and increases FAO. As Treg cells are very dependent on FAO, we studied the impact of 
PPAR $\beta / \delta$ pathway activation on human T cell polarization toward Tregs. In this objective, we cultured CD4+ T cells selected from monocyte-depleted human buffy coats and treated in vitro with TGF- $\beta(5 \mu \mathrm{g} / \mathrm{mL})$ to induce Treg polarization in the presence of DMSO (TREG) or GW0742 (TREG GW). We used the gating strategy presented in Figure 1C, namely a flow cytometry analysis of CD25+ FOXP3+ cells (Tregs) in CD3+CD4+ human T cells. The presence of TGF- $\beta$ in the culture medium of CD4+ T cells (Figure 1D, TREG) permitted to almost double $(1.94 \pm 0.09$, $\# p<0.0001)$ the percentage of CD25+ FOXP3+ cells (Tregs) in CD3+CD4+ human T cells compared to the condition without TGF- $\beta$ (Th0) and induced a slight but significant increase in FOXP3 mean fluorescent intensity (MFI) (Figure 1E, TREG, $1.104 \pm 0.04, \# p<0.05)$, considered to represent the mean content level of FOXP3 protein in cells. The activation of the PPAR $\beta / \delta$ pathway by GW0742 (Figure 1D, TREG GW) significantly favored Treg polarization in 14 independent experiments, as reflected by the increase in prevalence of CD25+ FOXP3+ cells in CD3+CD4+ human T cells (mean increase $14.9 \% \pm 3.1 \%$ ) without change in FOXP3 MFI. We, therefore, showed that activation of PPAR $\beta / \delta$ pathway in human blood $T$ cells leads to a change in $T$ cell metabolism, favoring FAO that is accompanied by an increase in Treg polarization. These changes could perhaps be used as a blood signature of the abuse of PPAR $\beta / \delta$ agonists by athletes.
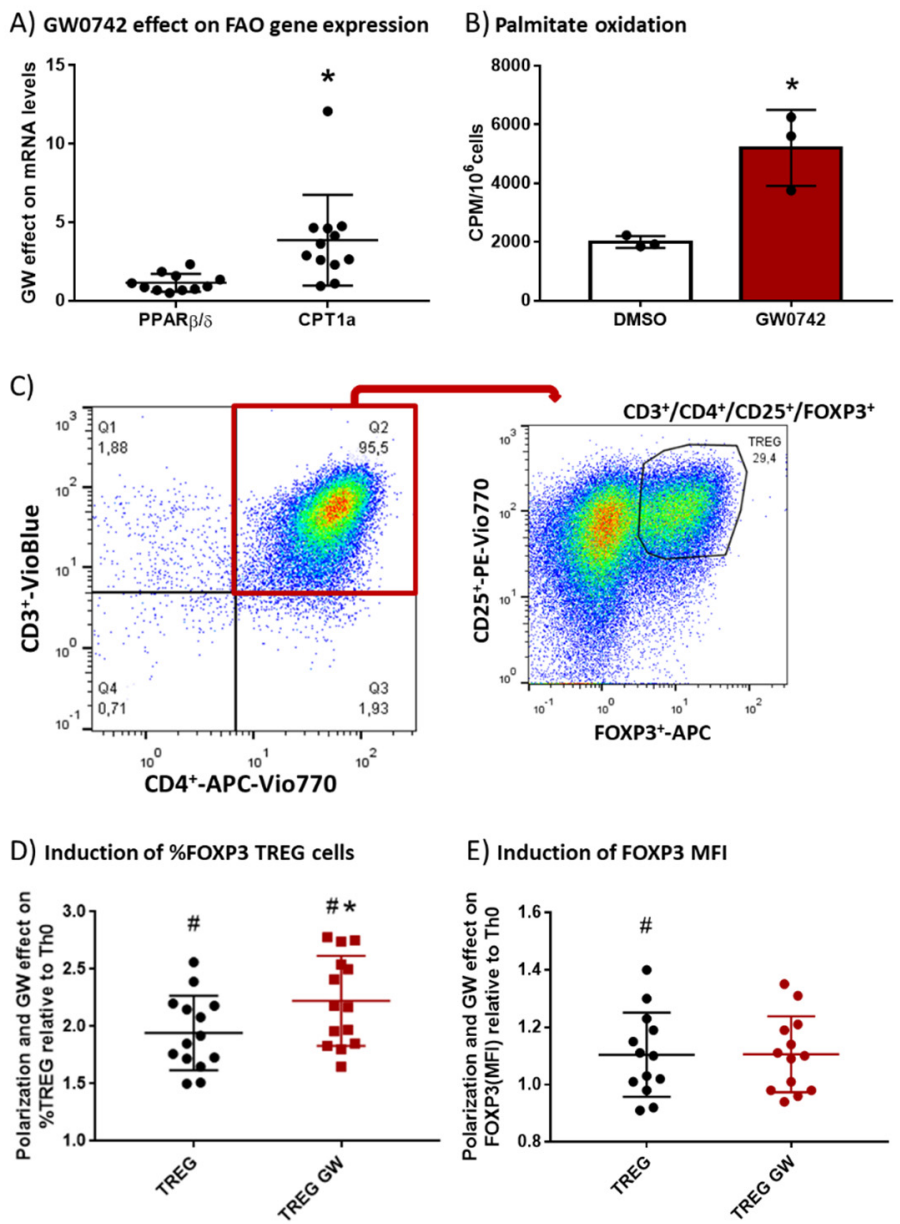

Figure 1. In vitro treatment of human T cells with GW0742 increases their FAO potential and their polarization in Tregs. (A) GW0742 $1 \mu \mathrm{M}$ effect (compared to DMSO, $n=8$ ) on PPAR $\beta / \delta$ and CPT1a mRNA level reported to RPL27 mRNA level used as housekeeping mRNA on monocyte-depleted human buffy coats activated with $\alpha \mathrm{CD} 3$ and $\alpha \mathrm{CD} 28$ antibody-coated beads and cultured for 6 days with human IL-2 (20 ng/mL). (B) Palmitate oxidation in isolated human CD4+ T cells. FAO was measured as ${ }^{3} \mathrm{H}$-palmitate conversion to ${ }^{3} \mathrm{H}_{2} \mathrm{O}$ and quantified as $\mathrm{CPM} / 10^{6}$ cells in in vitro-activated 
CD4+ cells treated with $1 \mu \mathrm{M} \mathrm{GW0742} \mathrm{or} \mathrm{DMSO}(n=3)$. (C) Gating strategy of flow cytometry analysis of CD25+ FOXP3+ cells (Tregs) in CD3+CD4+ human T cells. (D) Fold induction of prevalence (\%) of CD25+ FOXP3+ cells (Tregs) in enriched CD4+ T cells $(n=14)$ derived from monocyte-depleted human buffy coats treated in vitro with TGF- $\beta(5 \mu \mathrm{g} / \mathrm{mL})$ to induce Treg polarization in the presence of DMSO (TREG) or $1 \mu \mathrm{M}$ GW0742 (TREG GW) relative to Th0 cells (nonpolarized cells). (E) Fold induction of FOXP3+ MFI (mean fluorescent intensity) in CD4+ T cells $(n=14)$ derived from monocytedepleted human buffy coats treated in vitro with TGF- $\beta(5 \mu \mathrm{g} / \mathrm{mL})$ to induce Treg polarization in the presence of DMSO (TREG) or $1 \mu \mathrm{M}$ GW0742 (TREG GW) relative to Th0 cells. Data are shown as mean \pm SD. ${ }^{*} p<0.05$, GW effect; $\# p<0.05$, TREG vs. Th0 cells (univariate $t$-test).

\subsection{GW0742 Treatment Increases FAO Potential and Leads to Differential Changes in Treg Prevalence in Mouse Secondary Lymphoid Organs Depending on Training Status}

We first validated whether the potential signature that was detectable in human cells (i.e., increased FAO potential and Treg polarization) is specific for PPAR $\beta / \delta$ activation. We have previously demonstrated [6] that treatment of murine T cells with GW0742 increased palmitate oxidation and this effect was lost when the cells were co-treated with etomoxir, an inhibitor of CPT1a. We isolated CD4+ T cells from secondary lymphoid organs (SLO) of controls (Cre) or mice invalidated for PPAR $\beta / \delta$ in T cells (KO-T-PPAR $\beta / \delta$ ), treated the cells with $1 \mu \mathrm{M}$ of GW0742 for 6 days and studied the consequences on PPAR $\beta / \delta$ and CPT1a mRNA level. We showed, as seen in Figure 2A, that the treatment of control cells (CreTh0) with GW0742 did not alter the mRNA level of PPAR $\beta / \delta$. However, GW0742 treatment increased the mRNA level of CPT1a by a factor of 5 . This GW0742 effect seemed specific to its action on PPAR $\beta / \delta$, since the induction of CPT1a mRNA was markedly reduced in cells isolated from KO-T-PPAR $\beta / \delta$ mice (KOTh0).

To discriminate between the effects induced by chronic (training) bouts of exercise and PPAR $\beta / \delta$ activation, mice were trained on treadmills for 8 weeks and they were, or were not, treated with GW0742 mixed with food for 6 weeks ( $3 \mathrm{mg} / \mathrm{kg} \mathrm{BW} /$ day). At the end, the spleen and lymph nodes were harvested. GW0742 treatment led to an increase in PPAR $\beta / \delta$ mRNA levels in the lymph nodes but not in the spleen (Figure 2B,D). Moreover, the treatment of control mice with GW0742 for 6 weeks induced a significant increase in CPT1a mRNA by a factor of $3.3 \pm 1.5$ in the spleen (Figure $2 \mathrm{C}$ ) and $3.8 \pm 1.7$ in the lymph nodes (Figure $2 \mathrm{E}$ ). We did not detect a significant effect of training on PPAR $\beta / \delta$ or CPT1a mRNA levels in the SLO, nor did training alter the effects of GW0742 (Figure 2B-E). Regarding Treg prevalence, GW0742 treatment of mice did not significantly affect the percentage of FOXP3+ T cells (Tregs) in the lymph nodes of mice (Figure 2F), but exercise training independently of GW0742 treatment significantly increased this percentage and decreased the MFI level of FOXP3 (Figure 2F,G). However, there was a significant combined effect of GW0742 treatment and training, significantly increasing the proportion of Treg cells in lymph nodes (Figure 2F). It is noteworthy that the GW0742 treatment did not affect the FOXP3 MFI level of trained mice (Figure 2G). Thus, the GW0742 treatment of mice leads to immunometabolic changes promoting FAO potential and an increased proportion of Treg cells in exercise-trained mouse secondary lymphoid organs. 


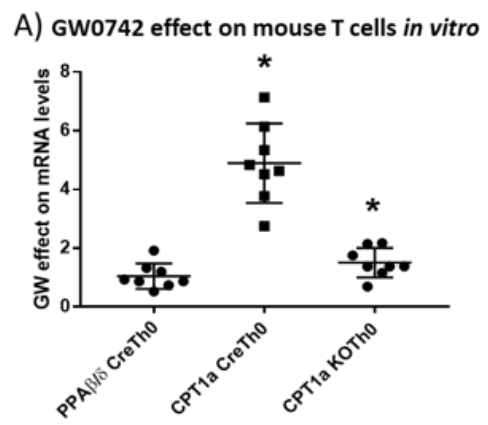

B) Spleen PPAR $\beta / \delta$

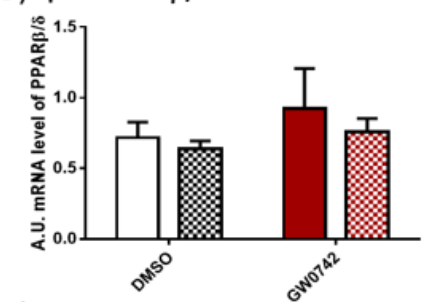

D) Lymph nodes PPAR $\beta / \delta$
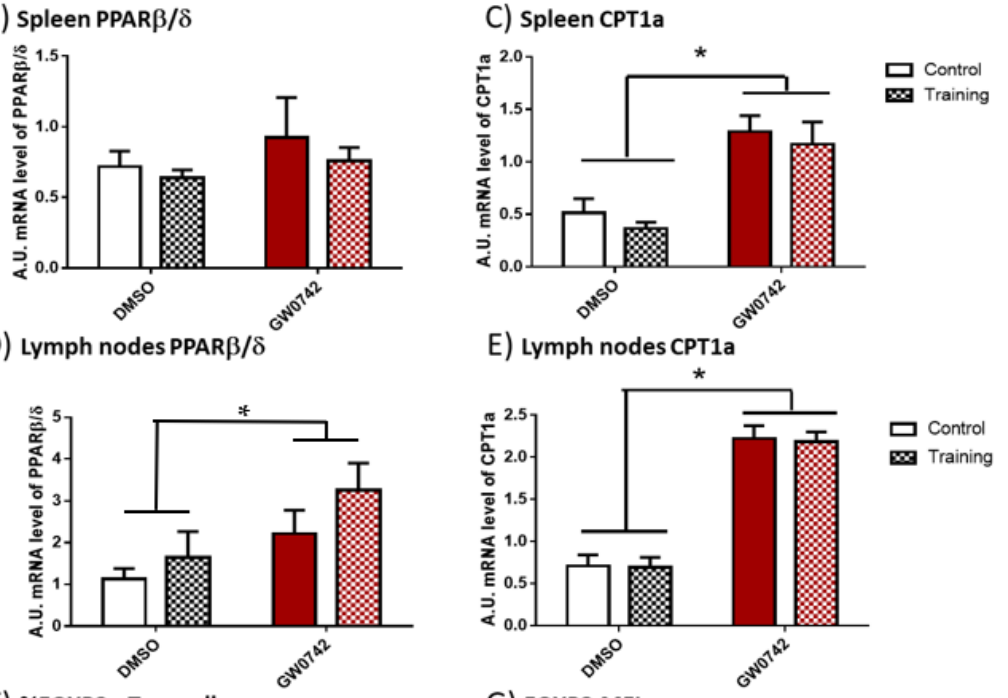

E) Lymph nodes CPT1a
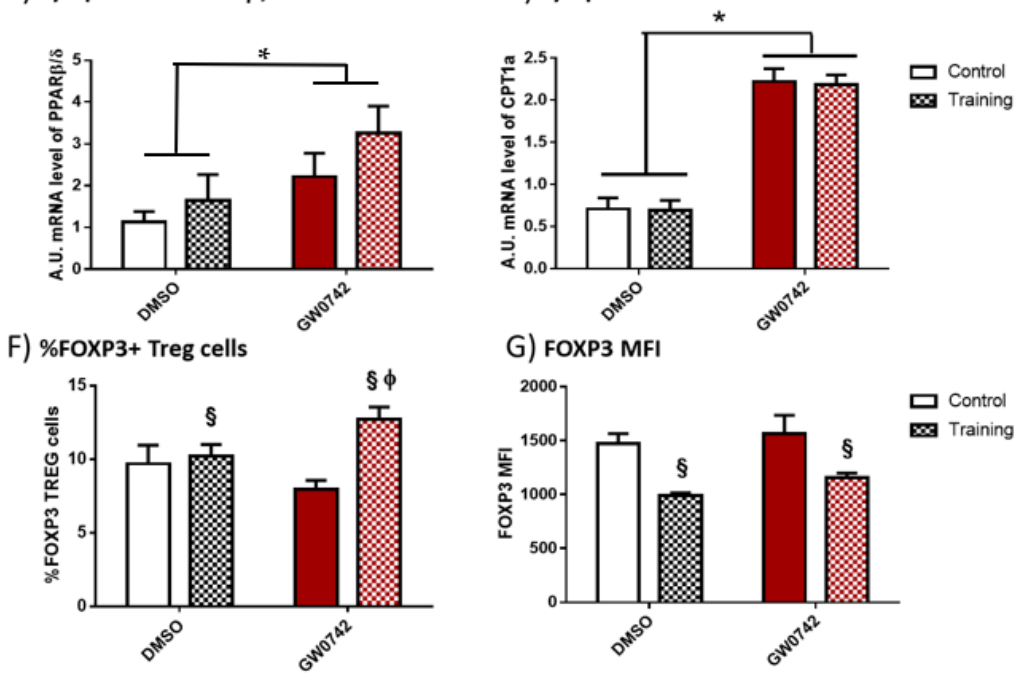

Figure 2. In vitro treatment of mouse T cells with GW0742 increases their FAO potential, and in vivo GW0742 treatment of mice leads to differential changes in FAO potential and Treg profile in the lymph nodes and spleen in trained mice. (A) The effect of $1 \mu \mathrm{M} \mathrm{GW0742} \mathrm{(compared} \mathrm{to} \mathrm{that} \mathrm{of} \mathrm{DMSO,}$ $n=6$ ) on PPAR $\beta / \delta$ and CPT1a mRNA levels normalized to 36B4 mRNA level used as housekeeping mRNA in CD4+ T cells from Lck-Cre (Cre) or KO-T-PPAR $\beta / \delta$ mice $(\mathrm{KO})$ activated with $\alpha \mathrm{CD} 3$ and $\alpha \mathrm{CD} 28$ antibodies coated-beads and cultured for 6 days with mouse IL-2 $(20 \mathrm{ng} / \mathrm{mL})$. (B) PPAR $\beta / \delta$ mRNA level and (C) CPT1a mRNA level in spleen; (D) PPAR $\beta / \delta$ mRNA level and (E) CPT1a mRNA level in lymph nodes, from control or trained mice ( 8 weeks, $n=6$ per group) treated, or not treated, for 6 weeks with GW0742 (3 mg/kg BW/day). (F) Prevalence (\%) of FOXP3+ cells (Tregs) in cells extracted from lymph nodes from control or trained mice ( 8 weeks, $n=6$ per group) treated, or not treated, for 6 weeks with GW0742 (3 mg/kg BW/day). (G) FOXP3+ MFI (mean fluorescent intensity) in cells extracted from lymph nodes from control or trained mice ( 8 weeks, $n=6$ per group) treated, or not treated, for 6 weeks with GW0742 ( $3 \mathrm{mg} / \mathrm{kg}$ BW/day). Data are shown as mean \pm SD. ${ }^{*} p<0.05$, GW0742 effect; $\S p<0.05$, training effect; and $\phi p<0.05$, interaction effect between training and GW0742 (two-way ANOVA).

\subsection{The Detection of GW0742 Effect on FAO Potential Is Masked in the Blood of Trained Mice}

In mice, we showed that increased PPAR $\beta / \delta$ activity leads to a defect in T cell development in the thymus with subsequent consequences on $\mathrm{T}$ cell populations in peripheral lymphoid organs, characterized by a decrease in the $\alpha \beta / \gamma \delta$ T cell ratio. This was accompa- 
nied by an increase in FAO potential and a concomitant increase in CPT1a mRNA levels in lymphoid organs [6,9]. To definitively validate this signature of increased PPAR $\beta / \delta$ activity, which could be detected in athletes' blood, its effects must be discriminated from those induced by acute and chronic (training) bouts of exhaustive exercise. We submitted mice to acute exercise, training ( 8 weeks), or long-term treatment (6 weeks) with GW0742 and studied the evolution in the blood of some signature markers $(\alpha \beta / \gamma \delta \mathrm{T}$ cell ratio, CPT1a mRNA levels). We also wanted to check whether the signature of the GW0742 use could be distinguished from that of physical training. We showed that the CD4+/CD8+ T cell ratio (Figure 3A) and the $\alpha \beta / \gamma \delta$ T cell ratio (Figure 3B) were not altered in the blood either by acute exercise, training, and GW0742 treatment, or by the combination of both GW0742 and training. We found (Figure 3C) that mRNA levels of CPT1a in the blood were not impaired by training but, in contrast, were significantly largely increased by treatment with GW0742 (4.04 \pm 3.03-fold increase). This measurement in blood cells of the CPT1a mRNA levels could, thus, constitute a signature of the use of the GW0742. However, and very surprisingly, we can see that the effect of GW0742 on CPT1a mRNA levels was largely and significantly decreased when GW0742 intake was combined with endurance training. Thus, the signature of the use of GW0742 is masked by endurance training, and the measurement of blood cell CPT1a mRNA levels will not be a reliable marker for the use of GW0742.
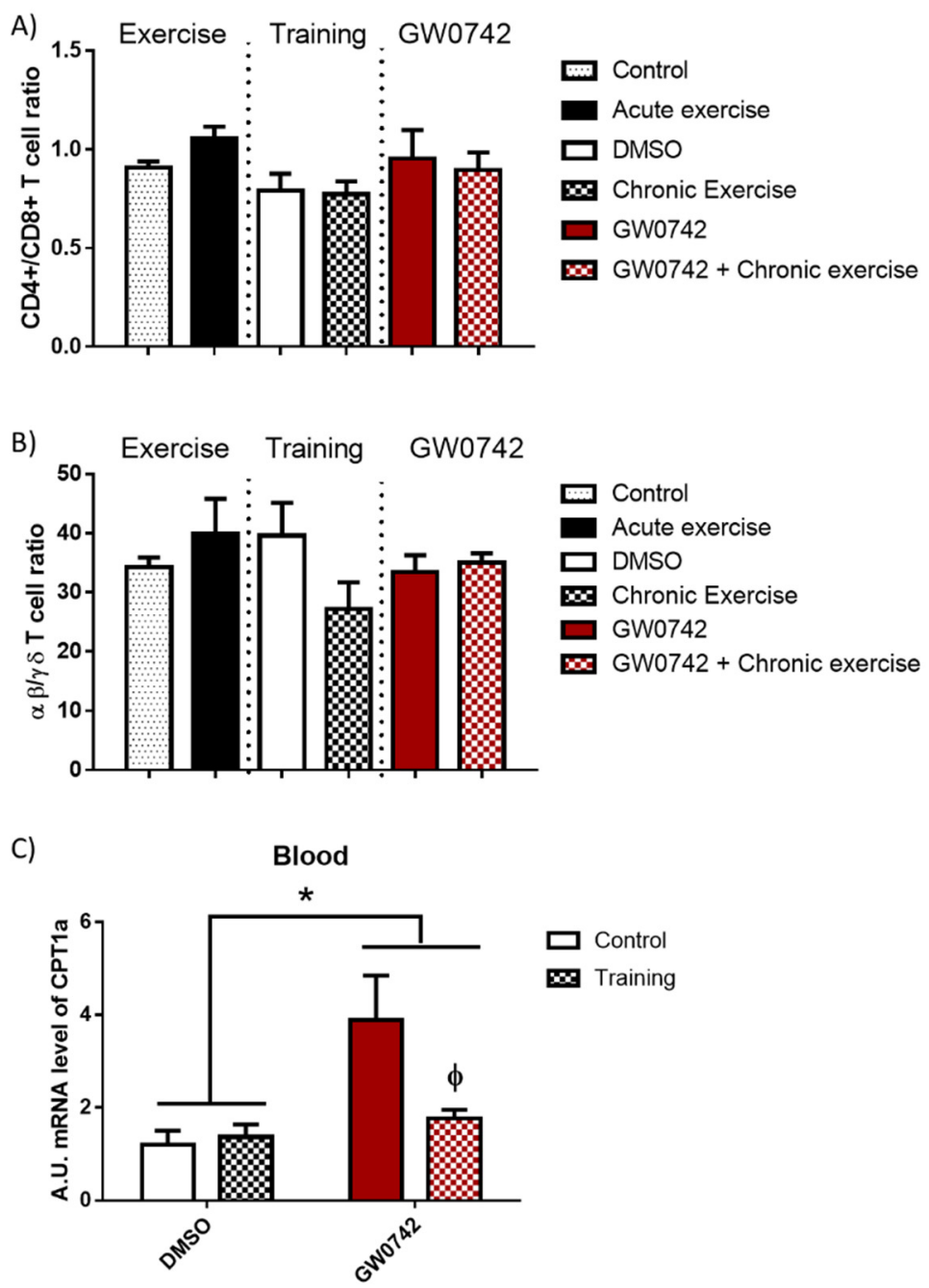

Figure 3. The $\mathrm{T}$ cell profile (CD4+/CD8+ T cell ratio, $\alpha \beta / \gamma \delta \mathrm{T}$ cell ratio) is unchanged in the blood by GW0742 treatment, exercise, or training. However, the detection in whole blood of GW0742's effects on the FAO potential is reduced by training. Mice were either subjected to or not given (control, $n=10)$ acute exercise on a treadmill with a slope of $5^{\circ}(n=8)$, the speed of the treadmill increased by 
$5 \mathrm{~cm} / \mathrm{s}$ every $15 \mathrm{~min}$ until mouse exhaustion. Another cohort of mice ( $n=6$ per group) was trained (chronic exercise) on a treadmill for 8 weeks, or not trained, and were then treated, or not treated (given DMSO instead), for 6 weeks with GW0742 (3 mg/kg BW/day). Blood mononuclear cells were isolated using Ficoll gradient, stained with fluorescence-conjugated antibodies, and analyzed with a BD FACS Canto II flow cytometer. (A) The CD4+/CD8+ T cell ratio was calculated; (B) the $\alpha \beta / \gamma \delta \mathrm{T}$ cell ratio was calculated; (C) the CPT1a mRNA level in blood cells was normalized by 36B4. Data are shown as mean \pm SD. ${ }^{*} p<0.05$, GW0742 effect, and $\phi p<0.05$, interaction effect between training and GW0742 (two-way ANOVA).

\section{Discussion}

T cells' function is intimately linked to their metabolic programs $[13,14]$. While Tregs rely heavily on FAO, they have found ways to adapt to different tissue types, such as tumors, to survive in competitive environments [15]. Mouse Treg cells generated through in vitro polarization of $\mathrm{CD}^{+} \mathrm{T}$ cells preferentially use FAO [16,17]. However, it is still controversial whether human Treg cell differentiation is dependent on FAO. We show here that the use of substances that activate PPAR $\beta / \delta$ can increase FAO in human T cells in vitro, and as a result increase the prevalence of Tregs. This result is important and new. Human Tregs are metabolically distinct from their mouse counterparts. It is known that ex vivo human Tregs are more glycolytic than ex vivo mouse Tregs [18]. This baseline difference may account for the magnitude of detectable metabolic changes that could be induced by either an endogenous or exogenous modulator of PPAR $\beta / \delta$ activity. Thus, we can assume that the whole-body GW0742 effect on immunometabolism would be more potent in humans compared to that in mice. Since our in vivo studies were conducted in mice, it is plausible that the effects observed in mice will be stronger in humans.

Whether exercise can modulate immune function by metabolic changes remains an underexplored area of research, and the ability of physical fitness or exercise to directly modify the metabolism of immune cells is unproven [12]. In obese mice, metabolic changes induced by exercise training were characterized by an increase in AMPK activity, both in lymphoid tissues and in skeletal muscle [9]. In both tissues, GW0742 treatment had complementary effects to exercise training on the decrease in inflammatory markers [9]. In the present study, in secondary lymphoid tissues, the induction of CPT1a expression was independent of exercise and was characteristic of the GW0742 effect on increasing FAO potential. The magnitude of CPT1a induction was high and suggests that the metabolism of immune cells (mainly T cells) was altered by GW0742 treatment. Furthermore, PPAR $\beta / \delta$ expression was also increased in lymph nodes by GW0742 treatment. However, the prevalence of Tregs was unchanged in the lymph nodes of sedentary mice treated with GW0742. Therefore, we can conclude that, even though GW0742 increased PPAR $\beta / \delta$ and CPT1a expression, it did not increase Treg prevalence in mice lymph nodes. Exercise training significantly decreased the MFI level of FOXP3 but interacted with GW0742, leading to an increase in the prevalence of Tregs. This increase appeared despite an absence of effect on CPT1a mRNA level in secondary lymphoid tissues. Together, these findings suggest that, at least in mice, CPT1a expression levels are disconnected from Treg prevalence. These results are entirely in line with the work of Raud et al. [19] that showed, using a mouse genetic model in which CPT1a was abrogated in T cells, that the ACC2/CPT1a axis is dispensable for Treg cell formation.

Despite an absence of effect on CPT1a mRNA level of exercise in SLOs, it is known that exercise impairs aspects of cellular immune function, probably due to the higher energy cost of exercise and metabolic perturbations in endurance athletes [20]. Indeed, a rapid metabolite turnover can be detected in seconds after an acute bout of endurance exercise, whereas it takes minutes to hours for transcriptomic and proteomic responses accounting for training adaptation [21]. An increase of about $75 \%$ of the maximum rate of fat oxidation (whole body measure), which is already high in elite endurance athletes, is observed after a $2 \mathrm{~h}$ recovery in a fasting condition from an endurance exercise session [22-24]. As both 
exercise and GW0742 alter fatty acid availability, we considered it important to choose the most appropriate experimental conditions in mice that allowed discriminating GW0742 effects from those induced by exercise, considering that the signature of an increase in FAO in T cells would be interpreted in an individual athletes' biological passport [25] as a doping signature. Information is available on the internet regarding the oral doses of GW0742 used by athletes for the purpose of doping. The oral dosages used comprise between 10 to $50 \mathrm{mg}$ per day for 4 to 8 weeks, which in terms of availability would correspond to a dose of $1-10 \mathrm{mg} / \mathrm{kg}$ administered in mice. Notably, the plasma concentration of the ligand at the $1 \mathrm{mg} / \mathrm{kg}$ dose in mice is shown to specifically activate PPAR $\beta / \delta$ [26]. We used a dosage/treatment period in our mouse studies that is quite close to the doping protocol used by athletes by administering a dose of $3 \mathrm{mg} / \mathrm{kg}$ persistently in food for 6 weeks. We used blood samples from trained mice to detect interactions between GW0742 and exercise training effects. GW0742 induced an increase in CPT1a mRNA, but surprisingly, this induction was masked by the training status of mice. This questioned the relevance of this signature for doping-control strategies. Another suggested alternative is based on our previous study that proposed the $\alpha \beta / \gamma \delta$ T cell ratio as a T cell signature to detect activity of the PPAR $\beta / \delta$ pathway [6]. We showed here that neither acute or chronic exercise nor GW0742 treatment changed this $\alpha \beta / \gamma \delta$ T cell ratio in mouse blood. Perhaps the 6week GW0742 treatment was not long enough for alterations in T cell development in the thymus to be reflected in the blood (our previous study examined transgenic mice that overexpressed PPAR $\beta / \delta$ in T cells constitutively).

Outside of the potential to use the latter observations to develop novel methods to detect the use of substances that activate the PPAR $\beta / \delta$ pathway, it should be noted that these novel discoveries also suggest that athletes who take PPAR $\beta / \delta$ agonists might seriously disturb their $\mathrm{T}$ cell homeostasis, thereby endangering the effectiveness of their immune system. Forcing FAO in CD4+ T cells would result in an increase in metabolic inflexibility. Depending on the (patho)physiological context, this could have either beneficial or deleterious consequences. The immunomodulatory effects of exercise might be mediated by the ability of exercise to adjust and improve Treg number and function [27]. An increase in Tregs would augment immune tolerance, thereby decreasing the risk of development of autoimmune diseases [28]. It should be noted in this context that physical exercise is known to decrease the risk of developing and is beneficial to the management of autoimmune disease [29]. Adipose tissue Tregs have been shown to play a beneficial role in decreasing insulin resistance associated with diet-induced obesity but a deleterious role in age-associated insulin resistance [30,31]. In the context of cancer, Tregs suppress anticancer immunity and, by doing so, hinder protective immunosurveillance of tumors and hamper effective antitumor immune responses [32]. A recent publication demonstrated that PPAR $\beta$ / $\delta$ plays an important role in Treg survival and function in tumors [33]. It was observed that intratumoral Tregs displayed increased expression of multiple PPAR $\beta / \delta$ target genes compared to Tregs from spleen and lymph nodes. Knocking out PPAR $\beta / \delta$ specifically in Tregs led to a reduction in intratumoral Treg accumulation accompanied by decreased tumor growth. Taken together, these data suggest that there is a real possibility that abuse of PPAR $\beta / \delta$ agonists for performance-enhancing purposes might lead to an increased cancer risk and/or a worse outcome when a tumor develops.

To conclude, we show here that the use of substances that activate PPAR $\beta / \delta$ can increase FAO in human T cells and as a result increase the prevalence of Tregs. It is unlikely that this signature could be used as a doping-control strategy in athlete's blood, since these immunometabolic changes are masked in mice by training status. Moreover, our study alerts on the risks of immune surveillance alterations with the use of PPAR $\beta / \delta$ activators in order to improve physical performance. 


\section{Materials and Methods}

\subsection{Animal Experiments}

\subsubsection{Acute Treadmill Exercise}

Twelve-week-old wild-type mice $(n=18)$ purchased from Charles River (Ecully, France) were accustomed to the treadmill (five-lane motorized treadmill, LE8710 M, Bioseb) a week before the running test was performed with a slope of $5^{\circ}(n=18)$. During a warm-up phase, the speed of the treadmill was progressively increased every 2 min for $10 \mathrm{~min}$ (5 to $25 \mathrm{~cm} / \mathrm{s}$ ). This phase was followed by an acute exercise phase where the speed of the treadmill was increased by $5 \mathrm{~cm} / \mathrm{s}$ every $15 \mathrm{~min}$ ( 30 to $40 \mathrm{~cm} / \mathrm{s}$ ) until the mice exhibited signs of exhaustion. The rear of the treadmill was equipped with a low-voltage electric stimulating bar to encourage each mouse to run. The bar was set to deliver $0.2 \mathrm{~mA}$ at a frequency of $0.25 \mathrm{~Hz}$, which caused an uncomfortable shock but did not injure the animal. The number of shocks was recorded, and the electric delivery was stopped if 50 shocks were reached.

\subsubsection{Physical Training and GW0742 Treatment of Mice}

We used 7-week-old C57Bl/6J wild-type mice purchased from Charles River (Ecully, France). Animals were maintained in a $12 \mathrm{~h}$ light, $12 \mathrm{~h}$ dark cycle and received food (A04 from UAR (Usine d'Alimentation Rationnelle), Villemoisson sur Orge, France) and water ad libitum. The mice were trained ( 8 weeks) on the five-lane treadmill. The training protocol was divided into three phases (Figure 4). The acclimatation phase lasted 4 weeks, during which the mice were trained in three sessions per week. The overload phase lasted 3 weeks, during which the mice were trained in five sessions per week. Finally, the tapering phase lasted 1 week, during which the mice were trained in three sessions. A training session lasted between 20 and $40 \mathrm{~min}$, the treadmill speed varied between 20 and $40 \mathrm{~cm} / \mathrm{s}$, and the belt was positively inclined at $5^{\circ}$. To encourage the mice to run, electrical $(0.2 \mathrm{~mA}-160 \mathrm{k} \Omega)$ and mechanical stimulation were used.

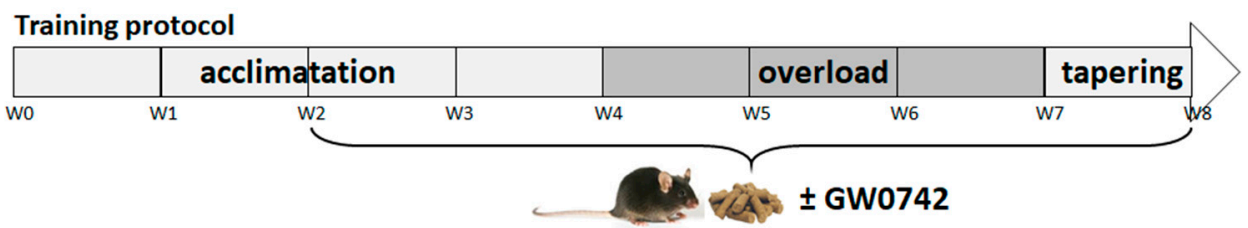

Figure 4. Training and GW0742 mouse treatment procedure.

After 2 weeks of acclimatation to training, mice received a normal chow diet (standard chow diet (A04)) administered ad libitum, supplemented with GW0742 (3 mg/kg BW/day) or with the vehicle (dimethyl sulfoxide, DMSO, $1 \%$ ). Food was reconstituted as described previously $[9,34]$. Twice a week, the food was refreshed, and animals were weighed.

Animals were sacrificed ( $90 \mathrm{~min}$ after acute exercise or $24 \mathrm{~h}$ after the last training session) by a lethal dose of intraperitoneal ketamine/xylazine $(100 / 16 \mathrm{mg} / \mathrm{kg})$. Blood samples were obtained by cardiac puncture.

\subsection{Mouse and Human T Cell Isolation and Treg Polarization}

Mouse CD4+ cells from control (Lck-Cre) or KO-T-PPAR $\beta$ / $\delta$ mice [35] were positively selected from secondary lymphoid organs (SLOs, consisting of the inguinal, brachial, and cervical lymph nodes and the spleen). CD4+ T cells were grown as previously described [36] at $4 \times 10^{5}$ cells/well in a 48-well plate in RPMI medium supplemented with $1 \mathrm{mM}$ sodium pyruvate, nonessential amino-acid $(1 \times), 1 \%$ penicillin/streptomycin, $10 \%$ fetal calf serum (FCS), and $50 \mu \mathrm{M} \beta$-mercaptoethanol. Activation beads, covalently bound to $\alpha \mathrm{CD} 3$ and $\alpha \mathrm{CD} 28$ antibodies, as well as mouse IL-2 $(20 \mathrm{ng} / \mathrm{mL})$, were added to the culture medium for the Th0 conditions, as well as PPAR $\beta / \delta$ agonist GW0742 $1 \mu \mathrm{M}$ or DMSO $(0.1 \%)$. Cell medium was complemented with an equal volume of fresh medium every three days. 
Human buffy coats from healthy donors (Établissement Français du Sang, Marseille, France) were used to collect PBMCs by Ficoll density gradient centrifugation. Monocytes were depleted by adherence to Primaria plates for $2 \mathrm{~h}$. The cells of the supernatant (enriched in T cells), or CD4+ T cells isolated by negative selection using a Miltenyi Biotec system (\#130-091-155), were plated at $4 \times 10^{5}$ cells /well in a 48-well plate. Activation beads coated with $\alpha \mathrm{CD} 3$ and $\alpha \mathrm{CD} 28$ antibodies, as well as human IL-2 $(20 \mathrm{ng} / \mathrm{mL})$, were added to the culture medium in presence or absence of GW0742 $(1 \mu \mathrm{M})$ or DMSO $(0.1 \%)$. After 6 days of activation, the cultures comprised over $95 \% \mathrm{~T}$ cells (data not shown). For Treg polarization experiments, TGF- $\beta(5 \mu \mathrm{g} / \mathrm{mL})$ was added to the culture medium for 6 days.

\subsection{Measurement of $\beta$-Oxidation Using ${ }^{3} \mathrm{H}$-Labeled Palmitate}

The isolated human CD4+ cells were cultured at $4 \times 10^{5}$ cells/well in a 48 -well plate in RPMI and were activated with anti-CD3/anti-CD28-coated beads. The palmitate $\beta$-oxidation was evaluated as previously described in [6,35,36]. Briefly, after 5 days of activation, for the last $24 \mathrm{~h}$, we added in the wells a mix of radioactive and nonradioactive palmitate coupled to BSA (2:1 ratio; $30 \mu \mathrm{M}$ Na-palmitate, $15 \mu \mathrm{M}$ fatty-acid-free BSA and $10 \mu \mathrm{Ci}\left(0.83 \mu \mathrm{M} 9,10-{ }^{3} \mathrm{H}-\right.$ palmitic acid (Perkin Elmer)). After a $24 \mathrm{~h}$ additional incubation, $100 \%$ trichloroacetic acid ( $10 \%$ final) was added to the cell suspensions, and proteins were precipitated. After centrifugation, $\mathrm{NaOH}$ (final concentration $0.75 \mathrm{M}$ ) was added to the supernatant to increase $\mathrm{pH}$ to 12 . Subsequently, $400 \mu \mathrm{L}$ of supernatant was applied to ion-exchange columns (Dowex $1 \times 2-400$ resin), and ${ }^{3} \mathrm{H}_{2} \mathrm{O}$ was recovered by eluting with $4 \mathrm{~mL}$ of $\mathrm{H}_{2} \mathrm{O}$. A $0.75 \mathrm{~mL}$ aliquot was then used for scintillation counting. Results were expressed as CPM (counts per minute) per $10^{6}$ cells.

\subsection{Cell Preparation and Flow Cytometry Analysis}

Human CD4+ in culture, mouse lymph node cell suspension (1 million), or blood mononuclear cells isolated using Ficoll gradient were stained with fluorescence-conjugated antibodies ( $\alpha$ CD3-VioBlue or $\alpha$ CD3-FITC, $\alpha$ CD4-APC-Vio770 or $\alpha$ CD4-APC, $\alpha$ CD25-PEVio, $\alpha$ FOXP3-APC, $\alpha$ TCR $\beta$-PEcy7, $\alpha$ TCR $\gamma \delta$-PE), and stained cells were analyzed with a BD FACS Canto II flow cytometer (BD Biosciences, Franklin Lakes, NJ, USA) using Miltenyi Biotec (Paris, France) antibodies. The extracellular labeling ( $\alpha \mathrm{CD} 3, \alpha \mathrm{CD} 4, \alpha \mathrm{TCR} \beta$, $\alpha \mathrm{TCR} \gamma$, and $\alpha \mathrm{CD} 25)$ was done at $4{ }^{\circ} \mathrm{C}$ for $20 \mathrm{~min}$. After two washes with PBS $0.5 \%$ FCS plus 2 mM EDTA, cells were permeabilized and fixed following the manufacturer's protocol (Miltenyi Biotec Kit). The intracellular staining was performed with $\alpha$ FOXP3 after the extracellular labeling. To determine the percentage of Tregs in a cell population, we discriminated CD3+CD4+ cells, and in this population, we gated FOXP3+ cells for mice cells and CD25+FOXP3+ cells for human cells, as shown in Figure 1C. Data were analyzed using FlowJo software.

\subsection{RNA Extraction and Quantitative Real-Time PCR}

Total RNA was extracted from cells or tissues with Trizol reagent (Invitrogen). For isolating RNA from blood, we used the kit Mouse RiboPure-Blood RNA Isolation (Applied Biosystems) following manufacturer procedure. Then, $1 \mu \mathrm{g}$ of RNA was reverse-transcribed using a QuantiTect Reverse Transcription Kit (Qiagen) on a Q-cycler II. Quantitative PCR was done using SYBR Premix Ex Taq (Tli RNase H Plus) (Ozyme) on a StepOne machine (Life Technologies). The relative amount of all mRNAs was calculated using the comparative $\Delta \Delta \mathrm{CT}$ method, and either 36B4 (for mice) or RPL27 (for humans) was used as the housekeeping gene. Primer sequences are available upon request.

\subsection{Statistical Analyses}

For each dependent variable under consideration, and according to assumptions for statistical analysis (i.e., normal distribution, equal variance), we performed the following: (1) nonparametric Mann-Whitney (in vitro study); (2) one-way ANOVA analysis (acute exercise effect); (3) two-way ANOVA analyses to investigate independent effects of GW0742 
treatment and exercise training, and the interaction effects between GW0742 and training. Statistical significance was accepted at $p<0.05$. The results are presented as means \pm standard deviations. All data were analyzed using StatView and GraphPad Prism v 5.0 software (San Diego, CA, USA).

Author Contributions: Conceptualization, B.S., A.-S.R. and J.G.N.; methodology, B.S., I.M.-S., G.L.M., D.L., S.L.G., E.B., J.M., C.M., N.L., J.G.N. and A.-S.R.; formal analysis, B.S. and A.-S.R.; investigation, B.S., A.-S.R., I.M.-S., G.L.M., D.L., S.L.G., E.B., J.M., C.M. and N.L.; data curation, B.S. and A.-S.R.; writing-original draft preparation, B.S., I.M.-S., J.G.N. and A.-S.R.; writing-review and editing, B.S., I.M.-S., G.L.M., D.L., S.L.G., E.B., J.M., C.M., N.L., G.C., J.G.N. and A.-S.R.; supervision, A.-S.R. and J.G.N.; project administration, A.-S.R. and J.G.N.; funding acquisition, A.-S.R., G.C. and J.G.N. All authors have read and agreed to the published version of the manuscript.

Funding: This work was funded by INSERM, the Université Côte d'Azur, the Fondation pour la Recherche Médicale (FRM, grant DRM20101220437) and the Agence Française de Lutte contre le Dopage (AFLD, grant R17020AA).

Institutional Review Board Statement: All mice experimental procedures were conducted at C3M according to French legislation, following the EU Directive 2010/63 for animal experiments, and were approved by the Institutional Ethic Committee for the Use of Laboratory Animals (CIEPAL-AZUR no. C2EA-28, N-2018110914193037).

Informed Consent Statement: Human blood samples form volunteers were obtained from the Etablissement Français du Sang (EFS) through authorization 2018-00131 and written consent was obtained by EFS for use of the blood for research purposes.

Data Availability Statement: The data presented in this study are available on request from the corresponding author.

Acknowledgments: The authors thank Véronique Corcelle and the animal facility staff (Unit1065, C3M, Institut National de la Santé et de la Recherche Médicale (INSERM)), for their excellent care of mice. The authors gratefully thank W. Wahli for sharing the B6.Ppard ${ }^{\mathrm{TM} 1 M t z}$ mice (that possess loxP sites up- and downstream of PPAR $\beta / \delta$ exon 4$)$.

Conflicts of Interest: The authors declare no conflict of interest.

\section{References}

1. Neels, J.G.; Grimaldi, P.A. Physiological functions of peroxisome proliferator-activated receptor beta. Physiol. Rev. 2014, 94, 795-858. [CrossRef] [PubMed]

2. Guerrieri, D.; Moon, H.Y.; van Praag, H. Exercise in a Pill: The Latest on Exercise-Mimetics. Brain Plast. 2017, 2, 153-169. [CrossRef] [PubMed]

3. Van der Gronde, T.; de Hon, O.; Haisma, H.J.; Pieters, T. Gene doping: An overview and current implications for athletes. Br. J. Sports Med. 2013, 47, 670-678. [CrossRef] [PubMed]

4. Trevisiol, S.; Moulard, Y.; Delcourt, V.; Jaubert, M.; Boyer, S.; Tendon, S.; Haryouli, H.; Taleb, W.; Caroff, M.; Chabot, B.; et al. Comprehensive characterization of the peroxisome proliferator activated receptor-delta agonist GW501516 for horse doping control analysis. Drug Test. Anal. 2021, 13, 1191-1202. [CrossRef]

5. Pokrywka, A.; Cholbinski, P.; Kaliszewski, P.; Kowalczyk, K.; Konczak, D.; Zembron-Lacny, A. Metabolic modulators of the exercise response: Doping control analysis of an agonist of the peroxisome proliferator-activated receptor delta (GW501516) and 5-aminoimidazole-4-carboxamide ribonucleotide (AICAR). J. Physiol. Pharmacol. 2014, 65, 469-476.

6. Mothe-Satney, I.; Murdaca, J.; Sibille, B.; Rousseau, A.S.; Squillace, R.; Le Menn, G.; Rekima, A.; Larbret, F.; Pele, J.; Verhasselt, V.; et al. A role for Peroxisome Proliferator-Activated Receptor Beta in T cell development. Sci. Rep. 2016, 6, 34317. [CrossRef] [PubMed]

7. Sakaguchi, S.; Yamaguchi, T.; Nomura, T.; Ono, M. Regulatory T cells and immune tolerance. Cell 2008, 133, 775-787. [CrossRef]

8. Newton, R.; Priyadharshini, B.; Turka, L.A. Immunometabolism of regulatory T cells. Nat. Immunol. 2016, 17, 618-625. [CrossRef] [PubMed]

9. Le Garf, S.; Murdaca, J.; Mothe-Satney, I.; Sibille, B.; Le Menn, G.; Chinetti, G.; Neels, J.G.; Rousseau, A.S. Complementary Immunometabolic Effects of Exercise and PPARbeta/delta Agonist in the Context of Diet-Induced Weight Loss in Obese Female Mice. Int. J. Mol. Sci. 2019, 20, 5182. [CrossRef]

10. Shaw, D.M.; Merien, F.; Braakhuis, A.; Dulson, D. T-cells and their cytokine production: The anti-inflammatory and immunosuppressive effects of strenuous exercise. Cytokine 2018, 104, 136-142. [CrossRef] [PubMed] 
11. Gleeson, M.; Bishop, N.C.; Stensel, D.J.; Lindley, M.R.; Mastana, S.S.; Nimmo, M.A. The anti-inflammatory effects of exercise: Mechanisms and implications for the prevention and treatment of disease. Nat. Rev. Immunol. 2011, 11, 607-615. [CrossRef]

12. Padilha, C.S.; Figueiredo, C.; Minuzzi, L.G.; Chimin, P.; Deminice, R.; Kruger, K.; Rosa-Neto, J.C.; Lira, F.S. Immunometabolic responses according to physical fitness status and lifelong exercise during aging: New roads for exercise immunology. Ageing Res. Rev. 2021, 68, 101341. [CrossRef]

13. Pearce, E.L.; Poffenberger, M.C.; Chang, C.H.; Jones, R.G. Fueling immunity: Insights into metabolism and lymphocyte function. Science 2013, 342, 1242454. [CrossRef] [PubMed]

14. Blagih, J.; Coulombe, F.; Vincent, E.E.; Dupuy, F.; Galicia-Vazquez, G.; Yurchenko, E.; Raissi, T.C.; van der Windt, G.J.; Viollet, B.; Pearce, E.L.; et al. The energy sensor AMPK regulates T cell metabolic adaptation and effector responses in vivo. Immunity 2015, 42, 41-54. [CrossRef] [PubMed]

15. Blagih, J.; Hennequart, M.; Zani, F. Tissue Nutrient Environments and Their Effect on Regulatory T Cell Biology. Front. Immunol. 2021, 12, 637960. [CrossRef]

16. Michalek, R.D.; Gerriets, V.A.; Jacobs, S.R.; Macintyre, A.N.; MacIver, N.J.; Mason, E.F.; Sullivan, S.A.; Nichols, A.G.; Rathmell, J.C. Cutting edge: Distinct glycolytic and lipid oxidative metabolic programs are essential for effector and regulatory CD4+ T cell subsets. J. Immunol. 2011, 186, 3299-3303. [CrossRef] [PubMed]

17. Gerriets, V.A.; Kishton, R.J.; Nichols, A.G.; Macintyre, A.N.; Inoue, M.; Ilkayeva, O.; Winter, P.S.; Liu, X.; Priyadharshini, B.; Slawinska, M.E.; et al. Metabolic programming and PDHK1 control CD4+ T cell subsets and inflammation. J. Clin. Investig. 2015, 125, 194-207. [CrossRef] [PubMed]

18. Procaccini, C.; Carbone, F.; Di Silvestre, D.; Brambilla, F.; De Rosa, V.; Galgani, M.; Faicchia, D.; Marone, G.; Tramontano, D.; Corona, M.; et al. The Proteomic Landscape of Human Ex Vivo Regulatory and Conventional T Cells Reveals Specific Metabolic Requirements. Immunity 2016, 44, 712. [CrossRef]

19. Raud, B.; Roy, D.G.; Divakaruni, A.S.; Tarasenko, T.N.; Franke, R.; Ma, E.H.; Samborska, B.; Hsieh, W.Y.; Wong, A.H.; Stuve, P.; et al. Etomoxir Actions on Regulatory and Memory T Cells Are Independent of Cptla-Mediated Fatty Acid Oxidation. Cell Metab. 2018, 28, 504-515.e7. [CrossRef] [PubMed]

20. Simpson, R.J.; Campbell, J.P.; Gleeson, M.; Kruger, K.; Nieman, D.C.; Pyne, D.B.; Turner, J.E.; Walsh, N.P. Can exercise affect immune function to increase susceptibility to infection? Exerc. Immunol. Rev. 2020, 26, 8-22. [PubMed]

21. Belhaj, M.R.; Lawler, N.G.; Hoffman, N.J. Metabolomics and Lipidomics: Expanding the Molecular Landscape of Exercise Biology. Metabolites 2021, 11, 151. [CrossRef] [PubMed]

22. Frandsen, J.; Poggi, A.I.; Ritz, C.; Larsen, S.; Dela, F.; Helge, J.W. Peak Fat Oxidation Rate Is Closely Associated With Plasma Free Fatty Acid Concentrations in Women; Similar to Men. Front. Physiol. 2021, 12, 696261. [CrossRef] [PubMed]

23. Frandsen, J.; Vest, S.D.; Ritz, C.; Larsen, S.; Dela, F.; Helge, J.W. Plasma free fatty acid concentration is closely tied to whole body peak fat oxidation rate during repeated exercise. J. Appl. Physiol. 2019, 126, 1563-1571. [CrossRef] [PubMed]

24. Andersson Hall, U.; Edin, F.; Pedersen, A.; Madsen, K. Whole-body fat oxidation increases more by prior exercise than overnight fasting in elite endurance athletes. Appl. Physiol. Nutr. Metab. 2016, 41, 430-437. [CrossRef]

25. Astolfi, T.; Crettaz von Roten, F.; Kayser, B.; Saugy, M.; Faiss, R. The Influence of Training Load on Hematological Athlete Biological Passport Variables in Elite Cyclists. Front. Sports Act. Living 2021, 3, 618285. [CrossRef] [PubMed]

26. Takata, Y.; Liu, J.; Yin, F.; Collins, A.R.; Lyon, C.J.; Lee, C.H.; Atkins, A.R.; Downes, M.; Barish, G.D.; Evans, R.M.; et al. PPARdeltamediated antiinflammatory mechanisms inhibit angiotensin II-accelerated atherosclerosis. Proc. Natl. Acad. Sci. USA 2008, 105, 4277-4282. [CrossRef]

27. Dorneles, G.P.; Dos Passos, A.A.Z.; Romao, P.R.T.; Peres, A. New Insights about Regulatory T Cells Distribution and Function with Exercise: The Role of Immunometabolism. Curr. Pharm. Des. 2020, 26, 979-990. [CrossRef]

28. Dominguez-Villar, M.; Hafler, D.A. Regulatory T cells in autoimmune disease. Nat. Immunol. 2018, 19, 665-673. [CrossRef] [PubMed]

29. Sharif, K.; Watad, A.; Bragazzi, N.L.; Lichtbroun, M.; Amital, H.; Shoenfeld, Y. Physical activity and autoimmune diseases: Get moving and manage the disease. Autoimmun. Rev. 2018, 17, 53-72. [CrossRef]

30. Feuerer, M.; Herrero, L.; Cipolletta, D.; Naaz, A.; Wong, J.; Nayer, A.; Lee, J.; Goldfine, A.B.; Benoist, C.; Shoelson, S.; et al. Lean, but not obese, fat is enriched for a unique population of regulatory T cells that affect metabolic parameters. Nat. Med. 2009, 15, 930-939. [CrossRef]

31. Bapat, S.P.; Myoung Suh, J.; Fang, S.; Liu, S.; Zhang, Y.; Cheng, A.; Zhou, C.; Liang, Y.; LeBlanc, M.; Liddle, C.; et al. Depletion of fat-resident Treg cells prevents age-associated insulin resistance. Nature 2015, 528, 137-141. [CrossRef] [PubMed]

32. Li, C.; Jiang, P.; Wei, S.; Xu, X.; Wang, J. Regulatory T cells in tumor microenvironment: New mechanisms, potential therapeutic strategies and future prospects. Mol. Cancer 2020, 19, 116. [CrossRef] [PubMed]

33. Wang, H.; Franco, F.; Tsui, Y.C.; Xie, X.; Trefny, M.P.; Zappasodi, R.; Mohmood, S.R.; Fernandez-Garcia, J.; Tsai, C.H.; Schulze, I.; et al. CD36-mediated metabolic adaptation supports regulatory T cell survival and function in tumors. Nat. Immunol. 2020, 21, 298-308. [CrossRef] [PubMed]

34. Mothe-Satney, I.; Piquet, J.; Murdaca, J.; Sibille, B.; Grimaldi, P.A.; Neels, J.G.; Rousseau, A.S. Peroxisome Proliferator Activated Receptor Beta (PPARbeta) activity increases the immune response and shortens the early phases of skeletal muscle regeneration. Biochimie 2017, 136, 33-41. [CrossRef] [PubMed] 
35. Rousseau, A.S.; Murdaca, J.; Le Menn, G.; Sibille, B.; Wahli, W.; Le Garf, S.; Chinetti, G.; Neels, J.G.; Mothe-Satney, I. Invalidation of the Transcriptional Modulator of Lipid Metabolism PPARbeta/delta in T Cells Prevents Age-Related Alteration of Body Composition and Loss of Endurance Capacity. Front. Physiol. 2021, 12, 587753. [CrossRef] [PubMed]

36. Le Garf, S.; Sibille, B.; Mothe-Satney, I.; Eininger, C.; Fauque, P.; Murdaca, J.; Chinetti, G.; Neels, J.G.; Rousseau, A.S. Alpha-lipoic acid supplementation increases the efficacy of exercise- and diet-induced obesity treatment and induces immunometabolic changes in female mice and women. FASEB J. 2021, 35, e21312. [CrossRef] 